\title{
Community-based study on renew or dropout status of social health insurance program in Bharatpur Metropolitan City, Chitwan
}

\author{
Chandan Subedi ${ }^{*}$, Eak Narayan Paudel${ }^{2}$, Subash Koirala ${ }^{3}$, Harishchandra Ghimire $^{4}$, \\ Amrita Paudel ${ }^{5}$ \\ *Corresponding author, email: chandansubedi5@gmail.com
}

\begin{abstract}
Background: Health insurance is emerging as the most preferred form of the health financing mechanism. Higher dropout puts a threat to governments target (Social health security program) of $100 \%$ enrolment by 2030 .This study aimed at accessing the factors associated with current SHI status (renew or dropout) in Bharatpur metropolitan city. Methods: The community based descriptive cross-sectional study using face to face interview was carried out in Bharatpur Metropolitan city, Chitwan. 342Household head that have enrolled in Social Health Insurance for past year are considered as a sample to describe the Renewal status among SHI Enroll household. We used Pearson's chisquare test to investigate the effect of some explanatory variables on renewal and dropout status of SHI.

Results: Among 342 household enroll SHI scheme, there were 203(59.4\%) Renewed for next year and 139(40.6\%) household dropout SHI Scheme. Results shows that current status of SHI (renew or dropout) differ significantly with Sex of household head $(P<0.01)$, education status $(P<0.01)$, family type $(P<0.01)$, highest level of education in family $(P<0.01))$, presence of children $(P<0.001)$, presence of pregnant women in family $(P=0.009)$, presence of ageing population in family $(P<0.001)$, Disability in family $(P=0.016)$, Chronic disease in family $(P<0.01)$.

Conclusion: The study concluded that the influence factors for Renew or Dropout status of SHI were: type of family, household education status, presence of children, pregnant women in family, the ageing population in family, presence of disability and chronic disease in the family.
\end{abstract}

Keywords: Community Based, drop out, renew, social health insurance

\section{Introduction}

Nepal as a member of the United Nations, is committed towards Sustainable Development Goals (SDGs) adopted by the United Nations General Assembly in September 2015. One of the goals of SDG i.e. SDG 3 focuses specifically on ensuring healthy lives and promoting well-being for all at all ages. Target 3.8 of SDG 3 achieving

\footnotetext{
${ }^{1}$ Health Office, Baitadi.

${ }^{2}$ Department of Community Medicine and School of Public Health, Chitwan Medical College, Bharatpur, Nepal

${ }^{3}$ Department of Community Medicine and School of Public Health, Chitwan Medical College, Bharatpur, Nepal

${ }^{4}$ Department of Community Medicine and School of Public Health, Chitwan Medical College, Bharatpur, Nepal

${ }^{5}$ Department of Community Medicine and School of Public Health, Chitwan Medical College, Bharatpur, Nepal
} 
universal health coverage (UHC), including financial risk protection, access to quality essential health-care services and access to safe, effective, quality and affordable essential medicines and vaccines for all - is the key to attaining the entire goal as well as the health-related targets of other SDG $(\mathrm{WHO}, 2016)$.

The constitution of Nepal 2072 has declared health as a fundamental right to its citizens ensuring "Every citizen shall have the right to free basic health services from the State, and no one shall be deprived of emergency health services (Parajuli:2020). The Government of Nepal formed a Social Health Security Development Committee as a legal framework to start implementing a social health security scheme (SHS) after the National Health Insurance Policy came out in 2013 (Pant,2017).

Health insurance is emerging as the most preferred form of health financing mechanism in situations where private out-of-pocket expenditures on health are significantly high and cost recovery strategies affect the healthcare (Gilson, 1998). The insurance mechanism helps the communities to pool their risks and transfers risks of unforeseeable healthcare costs for a pre-determined fixed premium thereby avoiding catastrophic financial burden (Griffin, 1992).

The Social Health Security Program (SHSP) is a social protection program of the Government of Nepal that aims to enable its citizens to access quality health care services without placing a financial burden on them. The SHSP is a family-based health insurance scheme implemented by the Social Health Security Development Committee. The households, communities and government are directly involved in this program. SHSP helps prevent people from falling into poverty due to health care costs i.e. catastrophic expenditure due to accidents or disease by combining prepayment and risk pooling with mutual support (Lohani,2018).

The government of Nepal had initiated Social Health Security Program from Kailali district in the FY 2072/73. The enrollment was started from 25 Chaitra 2072 and benefit policy was effective from 01 Jestha 2073. In Baglung and Ilam, enrollment process began in 15 Asar 2073 and policy was started from 01 Bhadra 2073. The program was gradually expanded in a phase-wise manner to other districts (Lohani, 2018).

In Chitwan, the registration process was started from 01 Asar 2074 and by the end of this month, the total number of enrollment was recorded to be 35,743 . This population comprised 16,914 males, 18,826 females and 3 others (Lohani, 2018).

Health system in Nepal faces daunting challenges such as unequal distribution of health care services, poor infrastructures, inadequate supply of essential drugs, poorly regulated private providers, inadequate budget allocation for health, and poor retention of human resources in rural areas (Mishra,2015). 
Evaluation of Nepal's earlier community-based health insurance (CBHI) schemes showed that CBHI introduced in Nepal since the 1970s suffered from low enrollment and retention of members as well as from a pro-rich bias (Mishra,2015).

According to the National Census of 2011, the population of Nepal was 26,494, 504 and the total enrollment population of fifteen districts as per records of IMIS was 228,113. This shows that, the total insurance enrollment of Nepal by the end of FY 2073/74 was 0.86 percent (Lohani, 2018)

In context of Chitwan, about 6.23\% of total household were enrolled from 01 Asar 2074 to 31 Asar 2074. The success of any health insurance program directly depends on the enrolment and renewal rates. Low enrollment and dropout are fatal for the viability of any health insurance program since decreasing risk pool and induce financial losses

Sustainability of SHI program is essential to achieve UHC and SDGs. Low enrollment and retention puts the sustainability of the scheme at risk (Mishra, 2015). Decreasing risk pool would squeeze resource mobilization and impel financial losses (Savitha, 2017).

Identification of factors that determine renewal decisions is important to redesign the scheme, its benefit package or channelize resources to remove barriers to renew. This study might provide recommendations for the improvement of Health insurance schemes within the context of the current health care financing landscape and policy development. This study would provide us with information to assess whether the program suffers from adverse selection, social exclusion and the role of socio-economic variables in renewal decisions.

\section{Methods}

The community based descriptive cross-sectional study using face to face interview was conducted between $19^{\text {th }}$ May 2019 and 19th June 2019. This study carried out in community household of Bharatpur metropolitan city, Chitwan. Sample size was calculated with prevalence $51 \%$ from previous study. According to Bhat and Jain (2007), prevalence of renewal of health insurance is 51\%, allowable error (d) was 5\% (Savitha, 2017). The total population (N) for the study is taken as 3097 (i.e. according to municipality profile total household of Bharatpur metropolitan city is 3097) using Cochran formula $n=z 2 p q / e^{2} a n d ~ n_{0}=n / 1+n / N$ for finite population. The sample size was 342. A self-designed semi structured questionnaire was used to obtain the SHI status (renew or dropout) characteristics of the study population. Ethical clearance was obtained from CMC-IRC (Ref: CMC-IRC 075/076-138). The pre-testing was done in a study area with similarities. The reliability of this research was tested by conducting a pilot test by taking $10 \%$ of the sample and tested by using Cronbach alpha in SPSS 20. As the value of Cronbach alpha was greater than 0.8 , we concluded that the research tool (questionnaire) is reliable. Validity tools tested by finding the content validity from pre-test data. The questionnaires will be translated into Nepali language. 
Community household head of Bharatpur metropolitan city who enroll on SHI scheme in previous year was taken as a study population Non probability Convenience sampling techniques was used among Household head. Collected data were manually checked and entered in epi data 3.1 and exported to IBM SPSS 20.0 version software for further analysis SHI status (Renew or dropout) is assessed by the descriptive analysis of the collected information. The significant factors of SHI status (renew or dropout) were identified using Pearson Chi-square test at $5 \%$ level of significant.

\section{Results}

Table 1: Current SHI status (renew or dropout) among community household of Bharatpur City ( $n=342)$

$\begin{array}{ll}\text { SHI Status } & \text { Frequency (\%) }\end{array}$

Renewed

203(59.4)

Dropout

$139(40.6)$

Among the $342 \mathrm{SHI}$ enroll households above half i.e. 203(59.4) renew the SHI scheme for next year and the remaining 139(40.6) household dropout SHI scheme.

Table 2: Association between insurance status (renew or dropout) and socio-demographic factors of household ( $n=342)$

\begin{tabular}{|c|c|c|c|c|}
\hline Characteristics & Number (\%) & $\begin{array}{c}\text { Renewed } \\
n=203(59.4 \%)\end{array}$ & $\begin{array}{l}\text { Non-Renewed } \\
n=139(40.6 \%)\end{array}$ & P-value \\
\hline \multicolumn{5}{|l|}{ Sex } \\
\hline Male & $213(62.28)$ & $93(43.6)$ & $120(56.4)$ & $<0.01 *$ \\
\hline Female & $129(37.7)$ & $110(85.2)$ & $19(14.8)$ & \\
\hline \multicolumn{5}{|l|}{ Marital Status } \\
\hline Single & $37(10.9)$ & $27(72.9)$ & $10(27.1)$ & 0.074 \\
\hline Married & $305(89.1)$ & $176(57.7)$ & $129(42.3)$ & \\
\hline \multicolumn{5}{|l|}{ Ethnicity } \\
\hline Brahmin and Chettri & $262(76.6)$ & $163(62.2)$ & $99(37.8)$ & \\
\hline Non- & $80(23.4)$ & $40(50)$ & $40(50)$ & 0.052 \\
\hline \multicolumn{5}{|l|}{ Brahmin/Chettri ${ }^{* *}$} \\
\hline \multicolumn{5}{|l|}{ Religion } \\
\hline Hindu & $336(98.2)$ & $200(59.5)$ & $136(40.5)$ & 0.0638 \\
\hline Non-Hindu ${ }^{* * *}$ & $6(1.8)$ & $3(50)$ & $3(50)$ & \\
\hline \multicolumn{5}{|l|}{ Education } \\
\hline Illiterate & $206(60.2 \%)$ & $140(67.9 \%)$ & $66(32.1 \%)$ & $<0.01^{*}$ \\
\hline Literate & $136(39.8 \%)$ & $63(46.3 \%)$ & $73(53.7 \%)$ & \\
\hline
\end{tabular}

*Denotes significant association with SHI status (Renew or dropout(Applying parsons chi-square test at 5\% level of significance). ** denotes janjati, Dalit.*** Buddhist, Christian and Muslim

On bivariate analysis Sex and education status of household, head were found significantly associated with the insurance status(renew/dropout) of the family (Table 3). 
Table 3: Association between social insurance status and socio-demographic factors of household ( $n=342)$

\begin{tabular}{|c|c|c|c|c|}
\hline Characteristics & Number (\%) & $\begin{array}{c}\text { Renewed } \\
n=203(59.4 \%)\end{array}$ & $\begin{array}{l}\text { Non-Renewed } \\
n=139(40.6 \%)\end{array}$ & P-value \\
\hline \multicolumn{5}{|l|}{ Family Type } \\
\hline Nuclear & $176(52)$ & $65(36.9)$ & $113(63.1)$ & $<0.001^{*}$ \\
\hline Extended & 164(48) & $138(84.1)$ & $26(15.9)$ & \\
\hline \multicolumn{5}{|c|}{$\begin{array}{l}\text { Highest Level of education in the } \\
\text { family }\end{array}$} \\
\hline Intermediate level or less & $210(71.4)$ & $84(40)$ & $126(60)$ & $<0.001^{*}$ \\
\hline University level or more & $132(38.6)$ & 119(90.1) & 13(9.9) & \\
\hline \multicolumn{5}{|l|}{ Main Income Source } \\
\hline Agriculture & $234(68.5)$ & $137(58.5)$ & $97(41.5)$ & 0.654 \\
\hline Other than Agriculture ${ }^{* *}$ & $108(32.6)$ & $66(61.1)$ & $42(38.9)$ & \\
\hline \multicolumn{5}{|l|}{ Children Below 5 Years } \\
\hline Having & $82(24)$ & $69(84.1)$ & 13(15.9) & $<0.001^{*}$ \\
\hline Not Having & $260(75.8)$ & $134(51.5)$ & $126(48.5)$ & \\
\hline \multicolumn{5}{|c|}{ Pregnant women in the Family } \\
\hline Having & $25(7.3)$ & $21(84)$ & $4(16)$ & $0.009 *$ \\
\hline Not Having & $320(92.7)$ & $182(56.8)$ & $135(43.2)$ & \\
\hline \multicolumn{5}{|l|}{ Aged Population >60 } \\
\hline Having & $152(44.5)$ & $134(88.1)$ & 18(11.9) & $<0.001^{*}$ \\
\hline Not Having & 190(55.6) & $69(36.3)$ & 121(63.7) & \\
\hline \multicolumn{5}{|l|}{ Disability in the family } \\
\hline Having & $18(5.3)$ & $15(83.3)$ & $3(16.7)$ & $0.016 *$ \\
\hline Not Having & 319(93.3) & $183(57.3)$ & $136(42.7)$ & \\
\hline \multicolumn{5}{|l|}{ Chronic Disease in Family } \\
\hline Having & 164(48) & 148(90.2) & $16(9.8)$ & $<0.001^{*}$ \\
\hline Not Having & $178(52.1)$ & $55(30.8)$ & 123(69.2) & \\
\hline
\end{tabular}

*Denotes significant association with SHI status (Renew or dropout (Applying pearsons chi-square test at 5\% level of significance), ** denotes business, service, foreign employment.

Insurance status was showed significant association with, type of the family, highest level of education in the family, presence of children below 5 years of age, presence of pregnant women in the family, presence of aged population in the family, presence of disability in the family and presence of chronic diseases in the family (Table 3)

\section{Discussion}

In this study, Insurance status in the SHI scheme was found significantly associated with sex of the household head. Previous study conducted to study enrolment factor obtained the similar result (Adhikari, 2018). However, this finding contrasts with a study conducted in rural Burkino Faso in Sub-Saharan Africa (Dong, 2009).

The effect of ethnic class was found to have no association with the insurance status of the household. This contrasts with the previous study conducted in Nepal on enrolment status (Adhikari, 2018). This study couldn't find any association between religion and insurance status in the SHI scheme, which is similar to the study mentioned above (Adhikari, 2018). 
Family characteristics has major influences on dependent variable in this study, type of the family was found to be significantly associated with the insurance status, which corresponds with the systematic review of low- and middleincome countries which studied factors for uptake and sustainability of community-based health insurance (Fadlallah, 2018).

Descriptive statistics shows the higher percentage of renewal among households which have children below 5 years of age and aged population above 60 years' age. The inferential statistics also shows that the presence of children below 5 and aged population in the family is highly significant with insurance status. This result is similar to the study conducted in India (Savitha, 2014).

This research also revealed that the education status of the household head and the highest level of education influenced the insurance status of the household $(p<0.01)$. This result corresponds with the study conducted in India (Savitha, 2017).

Family characteristics have major influences on the dependent variable in this study, type of the family was found to be significantly associated with the insurance status, which corresponds with the systematic review of low- and middle-income countries which studied factors for uptake and sustainability of community-based health insurance (Fadlallah, 2018).

\section{Conclusion}

The study concluded that approximately Renewal and Dropout status is equal. The unexpected result of dropout cannot meet the aims of the social protection program of the Government of Nepal to enable its citizens to access quality health care services without placing a financial burden on them. Type of Household head, Type of family, Sex of the household head, Education status of the household head and Level of education in the family were found to influence the renew or dropout decision of the SHI. Thus the encouragement of the program towards community peoples to ensure and increase enrolment and Renew of Health insurance scheme to achieve Universal Health Coverage.

\section{Author Disclosure}

\section{Acknowledgments}

I would like to thank all the faculty members of the Department of Public Health, Chitwan Medical College for their guidance throughout the process and my batchmates for their motivation and support.

\section{Funding Information}

This research received no grant from any funding agency.

\section{Author contributions}


Software: Amrita Paudel, Validation: Eak Narayan Paudel, Formal Analysis: Subash Koirala

Investigation: Chandan Subedi Data Curation: All, Writing - Original Draft: Chandan Subedi

Writing - Review \& Editing: Eak Narayan Paudel, Visualization: Subash Koirala

Supervision: Harish Chandra Ghimire

\section{Disclosure Statement / Conflict of interest}

The authors declare no conflict of interest.

\section{Ethical statement}

Ethical approval from IRC Chitwan Medical College.

\section{Data deposition}

Data have been used only for this paper.

\section{Author ORCID information}

Chandan Subedi: https://orcid.org/0000-0002-7536-3573

\section{References}

Adhikari, N., Wagle, R. R., Adhikari, D. R., Thapa, P., \& Adhikari, M. (2018). Factors affecting enrolment in the community-based health insurance scheme of Chandranigahapur hospital of Rautahat district. Journal of Nepal Health Research Council, 16(41), 378-384. Available from: http://nepmed.nhrc.gov.np/index.php/inhrc/article/view/6

Bhat, R., \& Jain, N. (2007). A study of factors affecting the renewal of health insurance policy. Available from: http://vslir.iima.ac.in:8080/jspui/handle/11718/193

Dong, H., De Allegri, M., Gnawali, D., Souares, A., \&Sauerborn, R. (2009). Drop-out analysis of community-based health insurance membership at Nouna, Burkina Faso. Health policy, 92(2-3), 174-179. Available from: https://www.sciencedirect.com/science/article/pii/S0168851009000815

Fadlallah, R., El-Jardali, F., Hemadi, N., Morsi, R. Z., Abou Abou Samra, C., Ahmad, A., ... \&Akl, E. A. (2018). Barriers and facilitators to implementation, uptake and sustainability of community-based health insurance schemes in low-and middle-income countries: a systematic review. International journal for equity in health, 17(1), 1-18. Available from: https://equityhealthj.biomedcentral.com/articles/10.1186/s12939-018$\underline{0721-4}$

Gilson, L. (1998). In defence and pursuit of equity. Social Science \& Medicine, 47(12), 1891-1896. Available from: https://www.sciencedirect.com/science/article/pii/S0277953698002172 
Griffin, C. C. (1992). Health care in Asia: a comparative study of cost and financing

Available from: https://www.cabdirect.org/cabdirect/abstract/19926713393

Lohani G. R. (2018). Social Health Security (Health Insurance) Program in Nepal. Available from:

https://publichealthupdate.com/social-health-security-health-insurance-program-in-nepal/

Mishra, S. R., Khanal, P., Karki, D. K., Kallestrup, P., \&Enemark, U. (2015). National health insurance policy in Nepal: challenges for implementation. Global health action, 8(1), 28763. Available from: https://www.tandfonline.com/doi/abs/10.3402/gha.v8.28763

World Health Organization. (2016). World health statistics 2016: monitoring health for the SDGs sustainable development goals. World Health Organization.

Pant, C. R. (2017). Health Insurance: New Beginning to Health Care in Nepal. Journal of Lumbini Medical College, 5(1), 1-2. Available from: https://ilmc.edu.np/index.php/JLMC/article/download/127/149

Parajuli, D. N. (2020). Ensuring Reproductive Rights of Women in Nepal: Law and Praxis. Researcher: A Research Journal of Culture and Society, 4(1), 41-62. Available from: https://www.nepjol.info/index.php/RESEARCHER/article/view/33811

Savitha, B. (2017). Why Members Dropout? An Evaluation of Factors Affecting Renewal in Micro Health Insurance. Journal of Health Management, 19(2), 292-303. Available from; https://journals.sagepub.com/doi/abs/10.1177/0972063417699691

Savitha, Factors Determining Renewal of Membership in Micro Health Insurance: Proc Third Int Conf Glob Business. Econ Financ Soc Sci (GB14Mumbai Conf Mumbai, India 19-21 December 2014 ISBN 978-1-941505-21-2 Pap ID M472 Factors. 2014;(December):0-11.Available from:

http://globalbizresearch.org/Mumbai_Conference/pdf/pdf/M472.pdf 